\title{
A simple method for the preparation and injection of gas mixtures into a gas chromatograph using a two-component device
}

\author{
Donval Jean-Pierre ${ }^{1, ~ *}$, Guyader Vivien ${ }^{1}$, Boissy E. ${ }^{2}$
}

\author{
1 Unité des Géosciences Marines Géosciences Marines, Laboratoire Cycles Géochimiques et \\ ressources IFREMER Centre de Brest, Plouzané, France \\ 2 Département Mesures Physiques, INSTITUT UNIVERSITAIRE DE TECHNOLOGIE, Lannion, France \\ * Corresponding author : Jean-Pierre Donval, email address : jpdonval@ifremer.fr
}

\begin{abstract}
:
Environmental sciences are expanding and are based on standardized and certified calibrations when measurements are required. When a gaseous composition is quantified, commercial standards are used. Here, we report on a two-component device for the preparation and injection of gas mixtures at the appropriate levels of pressure and volume. The two-component calibrator/injector can be used simultaneously or separately depending on the experimental objective but their combination is extremely effective for injecting gas mixtures at low concentrations. The quantity of gas introduced into a gas chromatograph with the injector can be adapted to the sensitivity of the detector or to avoid column overload. The calibrator provides for a large range of gas-mixture concentrations, from $\mathrm{ppm}$ to $\% \mathrm{~mol} / \mathrm{mol}$ with an error of preparation of around $1 \%$ and an accuracy of less than $3 \%$. This device prepares a variety of gas mixtures (hydrogen, methane and dioxide of carbon) which are compared with certified mixtures by means of gas chromatographic measurements. The results show good agreement between prepared and certified mixtures with a maximum difference of $2 \%$ which remains within the relative error of commercial stanard. In addition, the preparation of dissolved methane at different concentrations in seawater is presented as a direct application of the calibrator.
\end{abstract}

\section{Highlights}

Description of a device for injecting gas mixtures (gas injector). Description of a device for preparing gas mixtures (gas calibrator). Application of gas calibrator for preparation of $\mathrm{H} 2, \mathrm{CH} 4$ and $\mathrm{CO} 2$ mixtures: comparison with certified mixtures. Application of gas calibrator to enrich seawater with $\mathrm{CH} 4$.

Keywords : Gas mixtures, Gas chromatography, sampling valve, Methane, Hydrogen, Carbon Dioxide. 


\section{Introduction}

Gas concentrations are important data for use in diverse fields of science including biology-medicine [1,2,3], the atmosphere [4,5], energy [6], the petrochemical industry [7] and geology [8] . Gas measuring techniques include the use of gas sensors [9] and analytical devices $[10,11]$. These techniques require thorough calibration to relate the signal to a gas concentration. This step is always included in the quality procedure $[12,13]$. The analyst has the choice of two solutions: a commercial or self-prepared standard. When a great number of standards at different concentrations are necessary, a homemade preparation is more adapatable, particularly when the range of concentration is large and the calibration must be checked against several standards. Similarly, if the separation of compounds before their detection with the analytical method is insufficient, there is a risk of mutual interference [14] or overlapping peaks involving an algorithm of deconvolution [15] of two or more compounds. In which case, the compounds, causing these interferences, will be closely controlled: different standards at different concentrations are essential.

The two main methods for preparing gas reference mixtures are static or dynamic [16-20], although a specific method based on an exponential dilution also exists [21,22]. Of the analytical techniques devoted to gas analysis, gas chromatography [23-27] is still widely used due to its proven reliability and the possibility of integrating different type of detector depending on the compound family or the concentration range studied. Technical developments in micro gas chromatographs over the last few decades have been essential in rendering this technique portable [28].

This paper describes a two-component device named "gas calibrator" and "gas injector" specifically designed for two objectives: obtaining multi-gas mixtures at a suitable level of accuracy and injecting these mixtures (or unknown samples) at determined concentrations. For laboratory preparation of gas-mixtures, commercial devices use a dynamic method based on mass-flow controllers. The average mass-flow controller has a turn-down ratio insufficient to have gas mixtures at low concentration. For gas mixtures at low concentration, these systems become naturally more complex in design, and therefore costly; the consumption of gas is also high. The device presented here and named "gas calibrator" is an alternative solution to the dynamic method. Its procedure is based on a static, manometric method, enabling the gas calibrator to reach gas mixtures with a large range of concentration. The consumption of gas is low and consequently only bottles of small volume ( $<5$ liters) are required. Devices, based on a manometric method, exits for the preparation of gas mixtures at medium concentration (29) or with a mixing chamber which is necessary to homogenize (30). Our device prepares mixtures at low concentrations (ppm) and homogenization of gas in the 
calibrator is not necessary which has simplified its design. In an effort to develop a lowmaintenance, low-cost apparatus, this device is manual.

The gas injector, coupled to a gas chromatograph equipped with a gas valve, is essential to precisely adjust the volume and pressure of gas samples to be injected. By controlling both the pressure and volume entering the gas chromatograph, our device provides a fundamental alternative solution to injection with gas-tight syringes. It offers the advantage of injecting samples below or above atmospheric pressure while maintaining a level of pressure in the injector closed to the initial pressure of sample.

Here, we focused on the preparation of gas mixtures with the gas calibrator composed mainly of hydrogen $\left(\mathrm{H}_{2}\right)$, methane $\left(\mathrm{CH}_{4}\right)$ and carbon dioxide $\left(\mathrm{CO}_{2}\right)$.

To study the behavior of the gas calibrator, multi-gas mixtures were prepared in the same concentrations as commercially certified gas mixtures and compared by means of chromatographic measurements.

Due to its capacity and ease to use, our gas calibrator is suitable for other applications such as the enrichment of seawater with specific amounts of methane.

\section{Material and methods}

\subsection{Gas calibrator}

\subsubsection{Description}

Fig. 1 shows a shematic overview and a photo of the gas calibrator. It includes three essential components:

. A metallic one-liter capacity tank. An o-ring seal is placed between the cover and body of the tank.

. A miniature threaded 0-7 bar pressure transducer (Kulite Semiconductor Products, Leonia, New Jersey, United States; +/- 0.1\% full scale output) with a 1 mbar resolution display.

. Six integral bonnet angle-pattern needle valves (Swagelok). These valves are screwed onto the tank cover (NPT thread) and connected to the different gases with $1 / 8$ " tube fitting. They are respectively devoted to gas supply (Diluent gas, Gas 1, Gas 2 and Gas 3), vacuum and to connect the calibrator either to the injector, a micro gas chromatograph or for direct transfer to a storage flask.

A high vaccum pump is also used and recommended. For a lightweight system, it is also possible to use a micro pump similar to that used in a micro chromatograph or as described by Donval [27]. In the latter case, it is advisable to perform a thorough purge of the tank with the first gas injected. 
The system is not equipped with an internal temperature sensor but the tank is placed in an air-conditioned room. The procedure is fast and the pressure is measured at each step of gas injection, so as not to disrupt the final result. Temperature variation inside the tank during mixture preparation is discussed in section 3.2.

\subsubsection{Protocol for gas-mixture preparation}

Preparation takes place in three steps:

. Vacuum in the tank by opening the valve connected to a vacuum pump.

. Introduction of one or more gaseous compounds at pressure according the $\%$ fraction predetermined (opening of Gas 1, Gas 2 or Gas 3 valve)

. Introduction of the balance gas (opening of dilution gas valve).

Note that when the tank is connected to the different gas for the first time, all the tubes are purged and the quality of gas is checked by injection into the gas chromatograph.

For target concentrations lower than $10 \%$, the gas mixture is prepared with several steps of partial pumping and an addition of diluent gas. Table 1 shows the pressure parameters applied to reach a final concentration of $10.8 \mathrm{ppm} \mathrm{CH}_{4}$ in helium. The calculation is based on the Dalton's law of partial pressures where the total pressure in the tank is equal to the sum of partial pressures. At each step of dilution, if the operator introduces a pressure at a rate different to the predetermined quantity, the new concentration is calculated (Excel table in the supplementary section) and can be rectified at the next step to approach the desired concentration.

For multi-compound mixtures, the injection of gases into the tank is performed according to the increasing values of pressure. These different dilution steps may appear considerable when low concentrations are required (e.g. five steps for a $10.8 \mathrm{ppm}^{\mathrm{C}} \mathrm{CH}_{4}$ ), but they are however recommended to minimize error on the targeted concentration.

\subsection{Gas injector}

\subsubsection{Description}

The gas injector is presented in Fig.2. The gas injector is a homemade system in stainless steel. It is hexagonal in order to accommodate up to six elements:

. A miniature 0-7 bar pressure transducer connected to the top surface of the block unit. . A connection to the vacuum pump (bottom face).

. Two $1 / 8$ " tubes (lower rear) for 1 ) connecting the gas injector to the sampling valve of the $a$ chromatograph and 2) providing an auxiliary gas line (standard, pure gas, sample). 
. A female thread (lower front) for connecting the sample flask (equipped with a shut-off valve) containing the unknown sample or gas mixture transferred from the gas calibrator. On both sides of the gas injector, there are two stainless steel bellows on the sealed valves. To reduce the internal volume, the valve body is inside the stainless steel block and the handle is outside. The two valves are respectively devoted to shutting off the vacuum (Vv) and the auxiliary tube $(\mathrm{Vg})$, respectively.

As illustrated in Fig. 2 (part GC), the gas injector is connected to an 8-port valve (Valco Instruments Co. Inc, Schenkon, Switzerland) of a gas chromatograph. This valve has two sample loops (1/16 in. o.d.; $50 \mu \mathrm{l}$ and $1 \mathrm{ml})$ and a plug on one of the ports.

The choice of an 8-port valve was motivated by the possibility of injecting two different volume loops with a single valve, the amount of injected gas can thus be adapted by adjusting pressure or volume. Finally this system offers the advantage of reducing the consumption of the standard gas compared to a dynamic method and is more accurate than an injection with a gas tight syringe into a split/splitless injector. Moreover, a sample under and above atmospheric pressure can be injected without the risk of contamination if the code of practice, as described below, is observed.

\subsubsection{Code of practice}

Recommendations for use of the gas injector:

- Apply adequate vacuum across the system to eliminate the residual gases (air, previous sample.). A high vacuum is recommended especially for gas traces analysis.

. Ensure correct positioning of the sample valve to inject the right loop.

. Check the pressure sensor.

. After injection, the vacuum must be immediately restored in the gas injector. Indeed, at the end of analysis and due to valve programming, the injection valve returns to its original position, and the loop must be under vacuum to avoid injection of any residual sample. Note that the choice of sampling valve is highly important. Certified valves with low leak are available. A great attention should be paid to the sampling loop. Commercial loops are recommended because they are accurately sized, electrolytically cut and electrochemically polished to ensure square, burr-free ends. If two loops are used, their volume must be checked (see section 3.1). Should the analyst prefer self-made sampling loops, we recommend calibration with a commercial loop and/or if the volume is sufficient, to fill the loop with distilled water to provide its true volume. Other loop calibration procedures are available [31]. 


\subsection{Gas chromatographic measurements}

To evaluate the two devices, gas chromatographic measurements were carried out on a 7890A gas chromatograph (Agilent, Santa Clara, United States) and on a SRA R3000 micro gas chromatograph ( $\mu \mathrm{GC}$; SRA instruments, Lyon, FRANCE). The first is equipped with an 8port gas valve which includes $50 \mu \mathrm{l}$ and $1 \mathrm{ml}$ sample loops, a packed column (Porapak Q) and a flame ionization detector (FID). The FID is a highly sensitive detector and specifically used for $\mathrm{CH}_{4}$ analysis. Assesment of the gas injector and preparation of the $\mathrm{CH} 4$ mixtures were conducted with this chromatograph.

The $\mathrm{R} 3000 \mu \mathrm{GC}$ is designed to continuously separate and measure fixed gases and organic compound concentrations within three minutes. The three analytical modules of $\mu \mathrm{GC}$ sample small amount of gas and simultaneous inject in all modules to develop up to 3 chromatograms and one cumulative report. Module A (MS5A 25m 0,32mmx30 $\mathrm{mm}$ column) analyzes gases

such $\mathrm{H}_{2}, \mathrm{He}, \mathrm{O}_{2}, \mathrm{~N}_{2}, \mathrm{CH}_{4}$ and $\mathrm{CO}$. To improve sensibility on $\mathrm{H}_{2}$, a gas of high interest in ocean geochemistry, argon is used as the carrier gas. Module B (Poraplot U 8m $0,32 \mathrm{~mm} \times 30 \mu \mathrm{m})$ is devoted to $\mathrm{CH}_{4}$ and $\mathrm{CO}_{2}$. Gases such $\mathrm{H}_{2} \mathrm{~S}$ or $\mathrm{C}_{2} \mathrm{H}_{6}$ are also detected and well separated on this module. The third module, module $\mathrm{C}(\mathrm{OV}-114 \mathrm{~m} 0,32 \mathrm{mmx} 2 \mu \mathrm{m})$, is for $\mathrm{C}_{2}-\mathrm{C}_{6}$ hydrocarbon analysis. These three modules are equipped with a micro thermal detector ( $\mu$ TCD).

The data are collected and processed using the Thermo Scientific ${ }^{\mathrm{TM}}$ Dionex $^{\mathrm{TM}}$ Chromeleon $^{\mathrm{TM}}$ 6.8 software for Agilent 7890A and Soprane 3.5.1 for SRA R3000.

\section{Results and discussion}

\subsection{Study of the gas injector}

In order to explore the behavior of the gas injector as a function of the volume $(50 \mu 1$ and $1 \mathrm{ml})$ and pressure of the sampling loop, the gas chromatograph 7890A was used. As mentioned above, gas chromatographic measurements of $\mathrm{CH}_{4}$ were performed by means of a FID. Indeed, the linear dynamic range of the FID is a powerful resource for detecting linearity anomalies linked to the injection. Furthermore, the methane is quickly eluted, $0.6 \mathrm{~min}$ on a Porapak Q column at $110^{\circ} \mathrm{C}$ and $30 \mathrm{ml} / \mathrm{mn}$, and thus offers a narrow peak which limits the error thanks to peak integration.

If the injection valve has a single loop, the volume between the standard and unknown sample will be the same and therefore it is not necessary to take into account the "volume" parameter. The loop will often lead to a deviation in results due to the volume uncertainty. This problem is less critical for pressure, primarily thanks to good linearity of the sensor. 
Table 2 corresponds to injections of two standard commercial $\mathrm{CH}_{4}(107.8 \mathrm{ppm}$ and 1002ppm $\mathrm{CH}_{4}$ in Helium) with $50 \mu \mathrm{l}$ and $1 \mathrm{ml}$ loops. In order to focus only on the influence of loop volume, each standard was injected at the same pressure (1013mbar). This table provides some information on the gas injector.

When a sample is injected at atmospheric pressure, precision is low: the Relative Standard Deviation (R.S.D.) based on five injections is $0.2 \%$ for $1 \mathrm{ml}$ loop and $0.5 \%$ for $50 \mu 1$. Relative to the two loops, the ratio of $\mathrm{CH} 4$ peak area is 18.244 for $107.8 \mathrm{ppm} \mathrm{CH} 4$ standard and 18.248 for $1002 \mathrm{ppm}$. The ratio, according to the loop volumes specified by the supplier $(50 \mu \mathrm{l}$ and $1 \mathrm{ml})$, is 20 . This difference, around $9 \%$, is explained probably by the uncertainty of the inner diameter of the loop tube. Indeed, the smaller the sample loop, the higher the deviation. In practice, for sample quantification or calibration purposes, the best approach is to apply a correction factor if a $50 \mu 1$ loop is injected.

Fig. 3 corresponds to the injection of 107.8 and $1002 \mathrm{ppm} \mathrm{CH}_{4}$ standards at 100, 500, 1000, 1500 and 2000 mbar (absolute pressure) with $50 \mu 1$ and $1 \mathrm{ml}$ loops. On the pressure range studied, from 100 to $2000 \mathrm{mbar}$, and for the two loops and two standards, the linearity is clearly demonstrated with a minimum correlation coefficient $\left(r^{2}\right)$ of 0.9999 . This proves the good sealing of boths system below and above atmospheric pressure. Such airtightness is essential when unknown samples are close to atmospheric pressure, due to gas expansion in the gas injector. When samples are opened to the both systems, the pressure decreases and can reduce to below atmospheric pressure particularly in the case of several successive injections. This variation in pressure is essentially related to the volume of samples and the size of the loop.

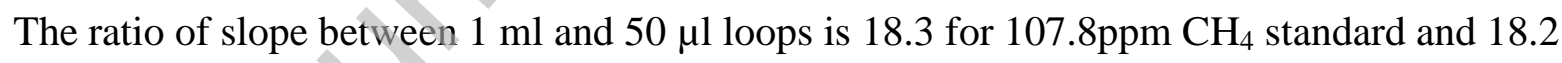
for $1002 \mathrm{ppm} \mathrm{CH}_{4}$ standard. These values are similar to those previously obtained with the 1 $\mathrm{ml}$ and $50 \mu 1$ loops (18.24). The volume of $1 \mathrm{ml}$ loop was determined by weighing the empty loop prior and post filling with distilled water at STP. A mean value of $995 \mu 1$ was obtained, based on 5 weighings (R.S.D.: 0.5\%). This concludes that the correct volume of $50 \mu 1$ loop is $995 / 18.2=54 \mu$ l. This correction will therefore be necessary when using this loop.

At this stage, two comments can be made. Firstly, it is possibe to perform calibration using only pure gas covering a range from 0.5 to $100 \%$ by injecting $50 \mu 1$ at 100 mbar and up to 1 $\mathrm{ml}$ at atmospheric pressure. Therefore, within this range, initial dilution by using the gas calibrator is not necessary. Similarly, we can inject an unknown sample below and above atmospheric pressure by corrected the pressure to remain within the standard. As mentioned above, the total quantity of gases injected can be adjusted to match detector sensitivity or to avoid column overload. This is beneficial when quantifying trace gases or conversely when it 
is more effective to reduce the injected quantity. Injection of a small quantity can bypass the problem when the conditions of separation on a column are insufficient.

3.2. Preparation of $\mathrm{CH}_{4}$ mixtures in helium with the gas calibrator

It should be noted that the design and specifications of the gas calibrator were defined according to the following criteria:

. Sealing from vacuum to 10 bar.

. Material comptible with the nature of gases.

. Total volume adapted for calibration, transfer to the gas injector and flask for long-term storage or specific application.

. Optimized geometry to quickly reach a natural homogenization.

. Manual control of gases instead of electronic control to reduce cost, maintenance and to obtain a compact and portable system.

. Minimization of the dead and intermediary volume to avoid "memory" effect between mixtures.

We started by testing the gas calibrator with simple $\mathrm{CH} 4$ mixtures. As explained in the previous paragraph, the formulated mixtures were analysed with the 7890A chromatograph equipped with an FID.

The following criteria were investigated:

. Conservation of linearity during consecutive dilutions.

. Precision when a mixture (same concentration) is prepared several times.

. Accuracy of obtained mixtures.

. Variation of precision and accuracy according to the total pressure in the tank and the level of reached $\mathrm{CH}_{4}$ concentration.

To study these criteria, three certified mixtures $\left(\mathrm{CH}_{4} 10.81 \pm 0.5 ; 107.8 \pm 5\right.$ and $1002 \pm 30$ ppm, confidence level $95 \%$, helium balance) were injected at 1013 mbar (five replicates). In addition, three mixtures (helium balance) at the same concentration as those certified were also prepared using the gas calibrator and pressure values mentioned in Table 1. These mixtures were also achieved according to two factors: independent preparation of five mixtures at each level of concentration and at two different total pressures, 1.7 bar and 5.1 bar. The aim was to respectively evaluate the error of preparation and observe the influence of total pressure in the tank.

Fig.4 represents the calibration curve with these three certified mixtures (red squared symbol). On this plot, we also report the $\mathrm{CH}_{4}$ peak area of three mixtures (black symbol) prepared with the gas calibrator to match the concentration of the certified mixtures. On the 
studied range, the three certified mixtures fit very well along a straight line with a $r^{2}$ value very close to 1 . This clearly proves that the initial concentrations of the three mixtures were maintained and were also injected in optimal conditions: purge of gas tubes, uncontaminated mixture. Furthermore, the black symbols (prepared mixtures) seem to be close to those of certified mixtures. The graph shows no significant difference in terms of precision and accuracy.

On Figure 5, the different concentrations of certified mixtures are plotted versus their mean peak area (confidence interval included) and compared with results of prepared mixtures. Regardless of the three prepared mixtures, there is no point outside the interval of confidence. However, if the total pressure is 1.7 bar or 5.1 bar, a difference in accuracy is obviously noted. When the total pressure is 1.7 bar, the measured values (peak area) of prepared mixtures are globally below certified mixtures and for a total pressure of 5.1 bar the trend is opposite. This applies to each prepared mixture but is more pronounced for the lower values. Results are proposed in the supplementary section (Table S1). Based on five replicates, the error of preparation in terms of precision is around $1 \%$ and does not vary with the level of concentration. In terms of accuracy, the difference between certified and prepared mixtures is inversely related to the concentration. This result is applicable both for prepared mixtures at 1.7 bar and those at 5.1 bar. The error of accuracy increases from 0.5 to $2.5 \%$ with a maximum difference for the $10.81 \mathrm{ppm}$ mixture. This error remains acceptable in relation the low concentration of mixture obtained. This is mainly due to the fact that the error of accuracy increases with the number of dilution steps and the associated error of sensor pressure and display resolution (1 mbar). The error does not increase incrementally but generally. Similarly, as noted in Fig 5, the deviation is negative for mixtures at 1.7 bar and positive at 5.1 bar.

A preliminary study was performed to question the need to provoke (or not) homogenization of mixture. Briefly, this study was conducted by means of two experiments: one based on natural homogenization and the other using a process of agitation. A magnetic bar was fixed on a propeller and both were placed in the tank. To activate the rotation of the propeller, a magnetic stirrer was placed below the tank. The results of both experiments are compiled in Table S2 (Supplementary section). The first injection was made 30 minutes after preparation of the mixture and the second 48 hours later. A two-sample t-test performed (Table S3 supplementary section) on each mixture at 30 minutes and $48 \mathrm{~h}$ does not show any significant difference between the averages (tstat $<\mathrm{t}$ Critical two-tail). However, the t-test performed on the mean between the two mixtures $(48 \mathrm{~h})$ does show a difference. This default 
is linked to the low error of measurement compared to the error of preparation but does not question the previous result.

These results clearly demonstrate that natural homogenization occurs rapidly, mostly due to the tank design. These results are in accordance with the equation of homogenization described by Hamon [32]: to minimize homogenization time, a tank of large diameter is preferred over a tank of great length. Furthermore, our operations take place in an airconditioned laboratory and do not involve great temperature variations. A test with a temperature sensor (NKE logger) inside the tank and data recorded over 24 hours result in a maximum deviation of $0.24^{\circ} \mathrm{C}$ (Fig S1; supplementary section). Over a short period, around 10 minutes (maximum preparation time), variation does not exceed $0.1^{\circ} \mathrm{C}$.

\subsection{Preparation of multi-gas mixtures with the gas calibrator}

In addition to the previous study (Section 3.2), the behavior of the calibrator was evaluated for use with multi-gas mixtures. Mixtures composed of $\mathrm{H}_{2}, \mathrm{CH}_{4}$ and $\mathrm{CO}_{2}$ were selected due to their particular interest in the marine geochemistry field. The aim was to compare certified mixtures with prepared mixtures. All analyses were performed with the aforementioned $\mathrm{R} 3000 \mu \mathrm{GC}$ but the gas injector was not used. Indeed, the $\mu \mathrm{GC}$ has its own injection system based on the MEMS (Micro Electromechanical System) technology. The quantity of injected gas depends on the injection time which varies from 50 to $300 \mathrm{~ms}$ and is defined in the analytical method by the operator. Injection time was fixed at $50 \mathrm{~ms}$ and integration parameters were rigorously the same for both prepared and certified mixtures but adjusted according to the level of concentration in order to enhance peak detection. Table 3 provides results based on the comparison of six standards with mixtures prepared at the same concentration. Except for two certified mixtures where the error is slightly above $2 \%$, for the three gases of interest $\left(\mathrm{H}_{2}, \mathrm{CH}_{4}\right.$ and $\left.\mathrm{CO}_{2}\right)$, the differences between homemade and certified mixtures does not exceed the error provided by the supplier on the certified value, highlighting the good agreement between the certified and our prepared mixtures. For helium $\left(\mathrm{H}_{\mathrm{e}}\right)$ and nitrogen $\left(\mathrm{N}_{2}\right)$, also measured by the $\mu \mathrm{GC}$, the correspondence also highlights good agreement. Thus, the calibrator seems to be suitable for these two others gases. We also observe a general trend on the differences between prepared and certified mixtures. The area values of prepared mixtures are globally under those of certified values. Since the total pressure of prepared mixture was $1.7 \mathrm{bar}$, this observation relates to the previous results (section 3.2) where the error between certified and prepared values is negative when a mixture is applied at 1.7 bar. 


\subsection{A specific application of the gas calibrator}

The main objective of the gas calibrator is to produce gas mixtures to calibrate analytical devices, but is also adapted for other applications. For example, it can be used to enrich water with an accurate quantity of gas to test a marine sensor or check/calibrate an analytical device directly measuring gases in water. Fig. 6 presents the system which consists of a stripping chamber (300 $\mathrm{ml}$ bulb with a glass frit and three stopcocks) connected to the tank where a mixture at 5.1 bar has been prepared. The chamber is filled with seawater and then purged with helium to remove the gases. The tank is then opened onto the chamber allowing the mixture to flush out the seawater. The flow is settled by a regulator inserted between the tank and the chamber. During this phase, the pressure inside the tank decreases and the flow varies from $100 \mathrm{ml} / \mathrm{min}$ to $25 \mathrm{ml} / \mathrm{min}$. In these conditions, the duration of the purge can theoretically last for up to 75 minutes. In practice, 15 minutes are sufficient. We tested $\mathrm{CH}_{4}$ mixtures concentrations ranging from 0.1 to $10 \%$. An aliquot of $5 \mathrm{ml}$ was transferred from the chamber into a headspace vial $(10 \mathrm{ml})$ and analysed with a headspace sampler connected to the 7890A gas chromatograph. A 10 minute time purge was applied. The data are compiled in Fig.7 and values in Table S4 (supplementary section). The method showed a good linear relationship between $\mathrm{CH}_{4}$ concentration of seawater and $\mathrm{CH}_{4}$ concentration in the tank with a satisfactory correlation coefficient $\left(r^{2}>0.999\right)$. The uncertainty defined as the relative standard deviation is $2 \%$ over the whole range of $\mathrm{CH}_{4}$ concentrations tested. In conclusion, under the conditions tested here, this technique ensures reliable results and is straightforward to implement. For larger volumes of seawater and up to 1 liter, 5 bar are sufficient to obtain similar results.

\section{Conclusion}

This paper describes a two-component device dedicated to preparing gas mixtures and capable of injecting them at determined pressure.

The gas injector is designed to be associated with a gas chromatograph equipped with a gas valve for injection. An 8-port valve is recommended. Two different volume loops are available for this configuration. Thus, the operator can adjust the pressure and volume of gas samples so as to inject the selected quantity. The main advantage of this device lies in the fact that the operator may inject at below and above atmospheric pressure while minimizing sample consumption as there is no dynamic purge of the loop. Note that when using pure gas, a calibration procedure is possible but only within a narrow range.

The advantages of the gas calibrator are the following. It is simple to produce a self-made gas mixture over a wide range of concentrations with correct uncertainty for the three 
considered gases $\left(\mathrm{CH}_{4}, \mathrm{H}_{2}\right.$ and, $\left.\mathrm{CO}_{2}\right)$. For a calibration with low uncertainty $(\leq 2 \%)$ the purchase of a commercial standard is however recommended. It is worth noting that the commercial standard can be diluted by using the gas calibrator. The transport of gas at high pressure is submitted to specific regulations and are costly. The gas calibrator allows to transfer and store prepared mixtures in small flasks at low pressures (100 $\mathrm{ml},<10 \mathrm{bar})$ and at diluted concentrations. The packaging is large enough to contain a great number of injections and particularly if the gas injector is used. This solution was adopted for oceanographic cruises to reduce the complications and in particular due to applicable legislation pertaining to the transport of inflammable gases.

\section{Acknowledgements}

The authors thank Alison Chalm and Cecile Cathalot for their her comments to improve this manuscript.

\section{Declaration of interests}

The authors declare that they have no known competing financial interests or personal relationships that could have appeared to influence the work reported in this paper.

Author contributions

Jean-Pierre Donval : Conceptualization, Methodology, Investigation, Experiments, Writing - Original Draft. Vivien Guyader : Validation, Experiments, Data analysis, Writing - Review

Emeric Boissy : Experiments, Data and formal analysis.

\section{References}

[1] M. Kajimura, R. Fukuda, R.M. Bateman, T. Yamamoto, M. Suematsu, Interactions of Multiple Gas-Transducing Systems: Hallmarks and Uncertainties of CO, NO, and H2S Gas Biology, Antioxidants \& Redox Signaling. 13 (2010) 157-192. https://doi.org/10.1089/ars.2009.2657.

[2] A. Nakao, Y. Toyoda, Book Review: Gas Biology Research in Clinical Practice, edited by Toshikazu Yoshikawa and Yuji Naito, Medical Gas Research. 1 (2011) 25. https://doi.org/10.1186/2045-9912-1-25.

[3] H. Müller, ed., Medical Gases, Wiley-VCH Verlag GmbH \& Co. KGaA, 2015. https://doi.org/10.1002/9783527676019.

[4] A.D. Richardson, D.Y. Hollinger, J.K. Shoemaker, H. Hughes, K. Savage, E.A. Davidson, Six years of ecosystem-atmosphere greenhouse gas fluxes measured in a sub-boreal forest, Sci Data. 6 (2019). https://doi.org/10.1038/s41597-019-0119-1.

[5] Gas Chromatography in the Analysis of Air Pollutants, Journal of Chromatography Library. (1991) 10-24. https://doi.org/10.1016/s0301-4770(08)61063-5. [6] H.-C. Sun, Y.-C. Huang, C.-M. Huang, A Review of Dissolved Gas Analysis in Power Transformers, Energy Procedia. 14 (2012) 1220-1225. https://doi.org/10.1016/j.egypro.2011.12.1079.

[7] J. Luong, R. Gras, H.J. Cortes, R.A. Shellie, Multidimensional gas chromatography for the characterization of permanent gases and light hydrocarbons in catalytic cracking process, 
Journal of Chromatography A. 1271 (2013) 185-191.

https://doi.org/10.1016/j.chroma.2012.11.025.

[8] J.L. Charlou, J.P. Donval, Y. Fouquet, H. Ondreas, J. Knoery, P. Cochonat, D. Levaché, Y. Poirier, P. Jean-Baptiste, E. Fourré, B. Chazallon, Physical and chemical characterization of gas hydrates and associated methane plumes in the Congo-Angola Basin, Chemical Geology. 205 (2004) 405-425.

https://doi.org/10.1016/j.chemgeo.2003.12.033.

[9] G. Korotcenkov Handbook of Gas Sensor Materials, Volume 1: Conventional Approaches, Wiley, 2013.

https://doi.org/1007/978-1-4614-7165-3

[10] C.Poole, Gas Chromatography, Elsevier, 2012.

https://doi.org/10.1016/c2010-0-66721-6.

[11] X. Mao, X. Zhou, Z. Gong, Q. Yu, An all-optical photoacoustic spectrometer for multigas analysis, Sensors and Actuators B: Chemical. 232 (2016) 251-256.

https://doi.org/10.1016/j.snb.2016.03.114.

[12] M.Słomińska, P. Konieczka, J. Namiesnik, Standard gas mixtures-indispensable

reference materials in the analysis of gaseous media, In TrAC Trends in Analytical

Chemistry, 29 (2010) 419-429.

https://doi.org/10.1016/j.trac.2010.02.003

[13] B. King, The Selection and Use of Reference Materials - A Basic Guide for Laboratories and Accreditation Bodies. Accredit. Qual. Assur. 8 (2003) 429-433.

https://doi.org/10.1007/s00769-003-0601-4.

[14] K. Malowany, J. Stix, A. Van Pelt, and G. Lucic, H2S interference on CO2 isotopic measurements using a PicarroG1101-i cavity ring-down spectrometer, Atmospheric

Measurement techniques, 8 (2015), 4075-7082.

https://doi.org/10.5194/amt-8-4075-2015.

[15] Z.-D. Zeng, S.-T. Chin, H.M. Hugel, P.J. Marriott, Simultaneous deconvolution and reconstruction of primary and secondary overlapping peak clusters in comprehensive twodimensional gas chromatography, Journal of Chromatography A. 1218 (2011) 2301-2310. https://doi.org/10.1016/j.chroma.2011.02.028.

[16] R.S. Barratt, The preparation of standard gas mixtures. A review, Analyst. 106 (1981)

817.

https://doi.org/10.1039/an9810600817.

[17] M. Słomińska, P. Konieczka, J. Namieśnik, New developments in preparation and use of standard gas mixtures, TrAC Trends in Analytical Chemistry. 62 (2014) 135-143.

https://doi.org/10.1016/j.trac.2014.07.013.

[18] M.J.T. Milton, G.M. Vargha, A.S. Brown, Gravimetric methods for the preparation of standard gas mixtures, Metrologia. 48 (2011) R1-R9.

https://doi.org/10.1088/0026-1394/48/5/r01.

[19] G. Nelson, Gas Mixtures, Routledge, 2018.

https://doi.org/10.1201/9780203755105.

[20] C. Fijało, T. Dymerski, J. Gębicki, J. Namieśnik, Devices for the Production of

Reference Gas Mixtures, Critical Reviews in Analytical Chemistry. 46 (2016) 361-373.

https://doi.org/10.1080/10408347.2014.953672.

[21] S. Greenhouse, F. Andrawes, Generation of gaseous standards using exponential dilution flasks in series, Analytica Chimica Acta. 236 (1990) 221-226.

https://doi.org/10.1016/s0003-2670(00)83315-2.

[22] J.J. Ritter, N.K. Adams, Exponential dilution as a calibration technique, Anal. Chem. 48 (1976) 612-619.

https://doi.org/10.1021/ac60367a017. 
[23] A. Lelevic, V. Souchon, M. Moreaud, C. Lorentz, C. Geantet, Gas chromatography vacuum ultraviolet spectroscopy: A review, J. Sep. Sci. 43 (2019) 150-173.

https://doi.org/10.1002/jssc.201900770.

[24] L. Bai, J. Smuts, P. Walsh, H. Fan, Z. Hildenbrand, D. Wong, D. Wetz, K.A. Schug, Permanent gas analysis using gas chromatography with vacuum ultraviolet detection, Journal of Chromatography A. 1388 (2015) 244-250.

https://doi.org/10.1016/j.chroma.2015.02.007.

[25] J. Beens, The role of gas chromatography in compositional analyses in the petroleum industry, TrAC Trends in Analytical Chemistry. 19 (2000) 260-275.

https://doi.org/10.1016/s0165-9936(99)00205-8.

[26] S. Pravallika, Gas Chromatography a Mini Review Research and Reviews Journal of Pharmaceutical Analysis, 5, 2 (2016) 55-62

[27] J.P. Donval, V. Guyader, Analysis of hydrogen and methane in seawater by "Headspace" method: Determination at trace level with an automatic headspace sampler, Talanta. 162 (2017) 408-414. https://doi.org/10.1016/j.talanta.2016.10.034.

[28] E. Lussac, R. Barattin, P. Cardinael, V. Agasse, Review on Micro-Gas Analyzer Systems: Feasibility, Separations and Applications, Critical Reviews in Analytical Chemistry. 46 (2016) 455-468. https://doi.org/10.1080/10408347.2016.1150153.

[29] W. Muniak, Z. Witkiewicz, E. Woryna, E. Kusińska, A. Twardowski, B. Goca, Preparation of standard gaseous mixtures by a manometric method using the BenedictWebb-Rubin equation, Journal of Chromatography A. 436 (1988) 323-327.

https://doi.org/10.1016/s0021-9673(00)94590-4.

[30] H.V. Dantas, M.F. Barbosa, P.N.T. Moreira, R.K.H. Galvão, M.C.U. Araújo, An automatic system for accurate preparation of gas mixtures, Microchemical Journal. 119 (2015) 123-127.

https://doi.org/10.1016/j.microc.2014.11.011.

[31] S.A. Smirnova, A.G. Vitenberg, B.V. Stolyarov, Determination of the volume of the gas sampling valve for chromatographs, Journal of Chromatography A. 170 (1979) 419-422. https://doi.org/10.1016/s0021-9673(00)95469-4.

[32] B. Hamon, Mélange de gaz, Techniques de l’ingénieur A5830 (1988) 1-15. 


\section{Journal Pre-proof}
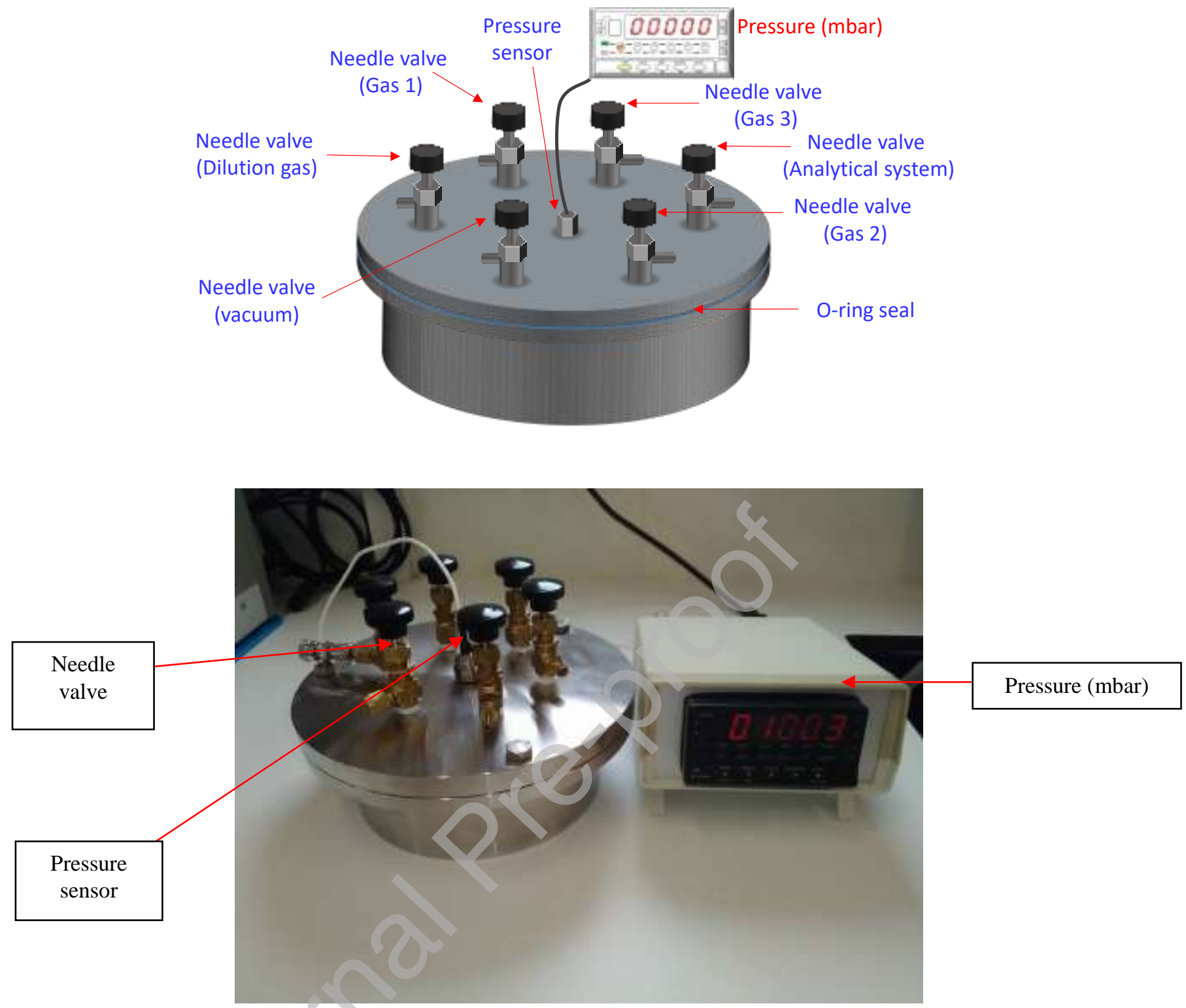

Fig.1: Schematic overview of the gas calibrator, one-liter capacity, internal dimensions: $152 \mathrm{~mm}$ diameter and $55 \mathrm{~mm}$ height (A), and photo of the gas calibrator (B).

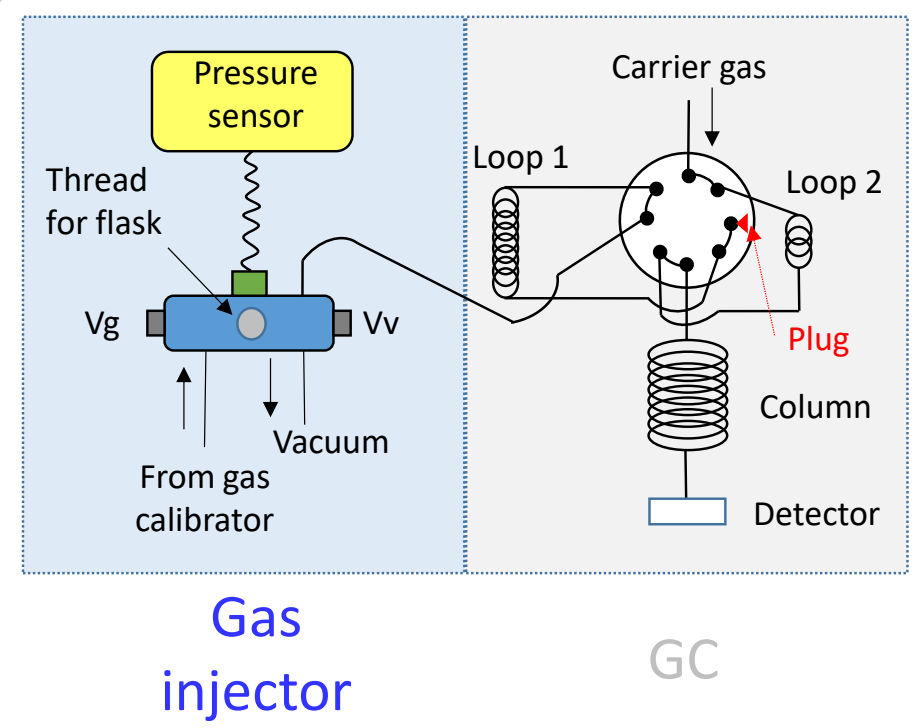


(A)

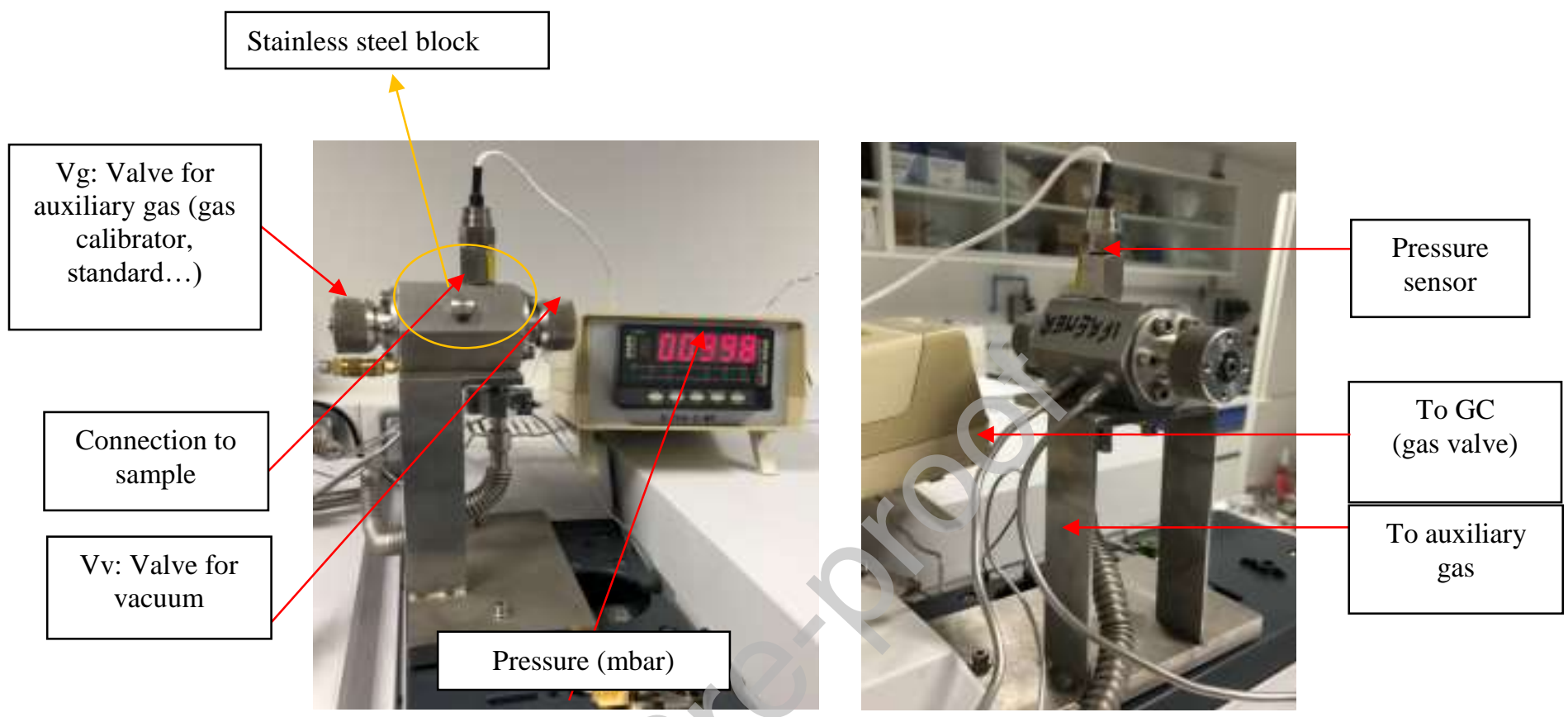

(B)

Fig. 2: Schematic diagram of the gas injector (A), and photos of the gas injector (B)

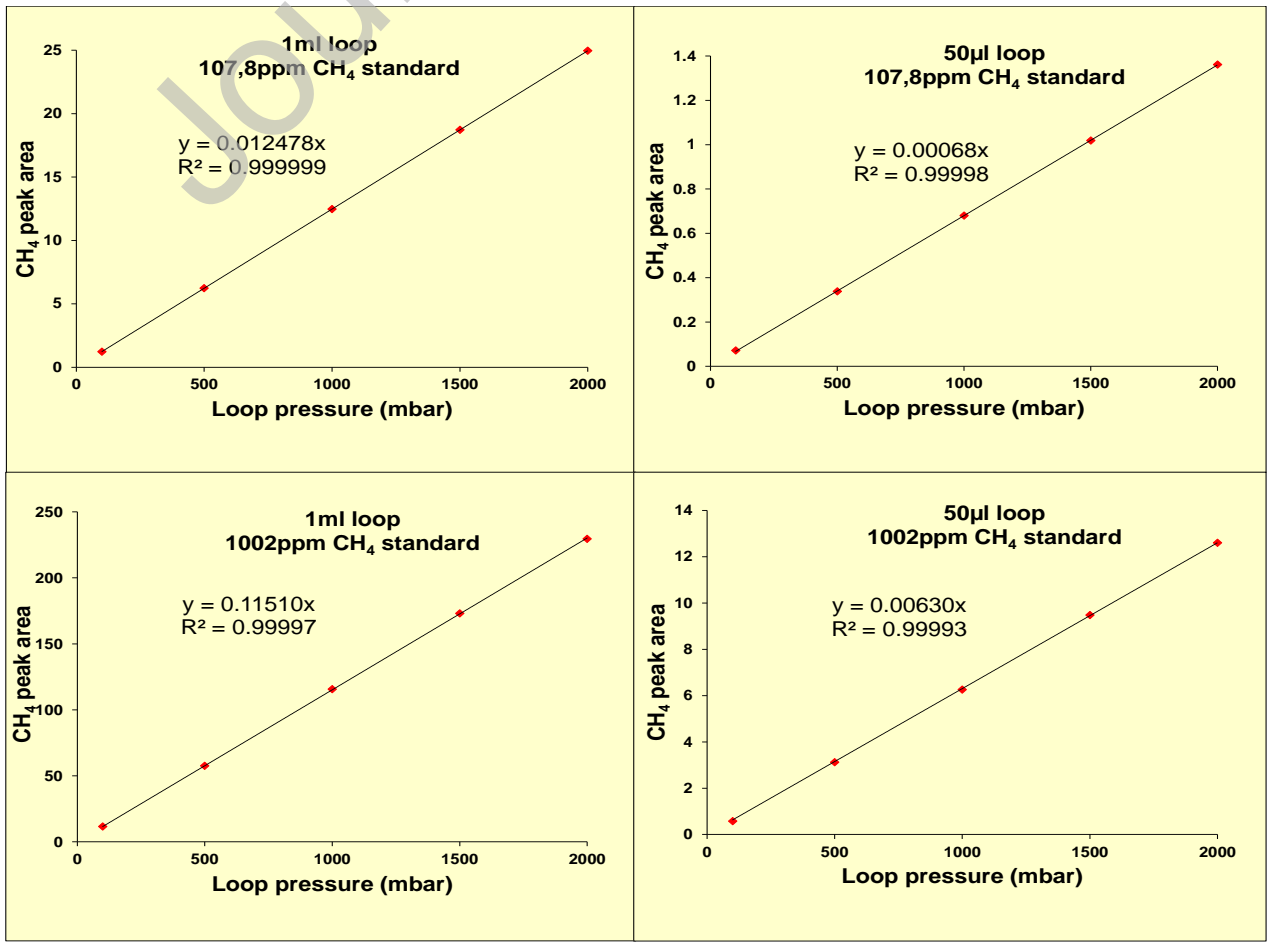


Fig. 3: Linear fit between $\mathrm{CH} 4$ peak area and loop pressure: injection of 107.8 and 1002 ppm $\mathrm{CH} 4$ standards at $100,500,1000,1500$ and 2000 mbar (absolute pressure) with $50 \mu 1$ and $1 \mathrm{ml}$ loops. (Red symbol: CH4 area).

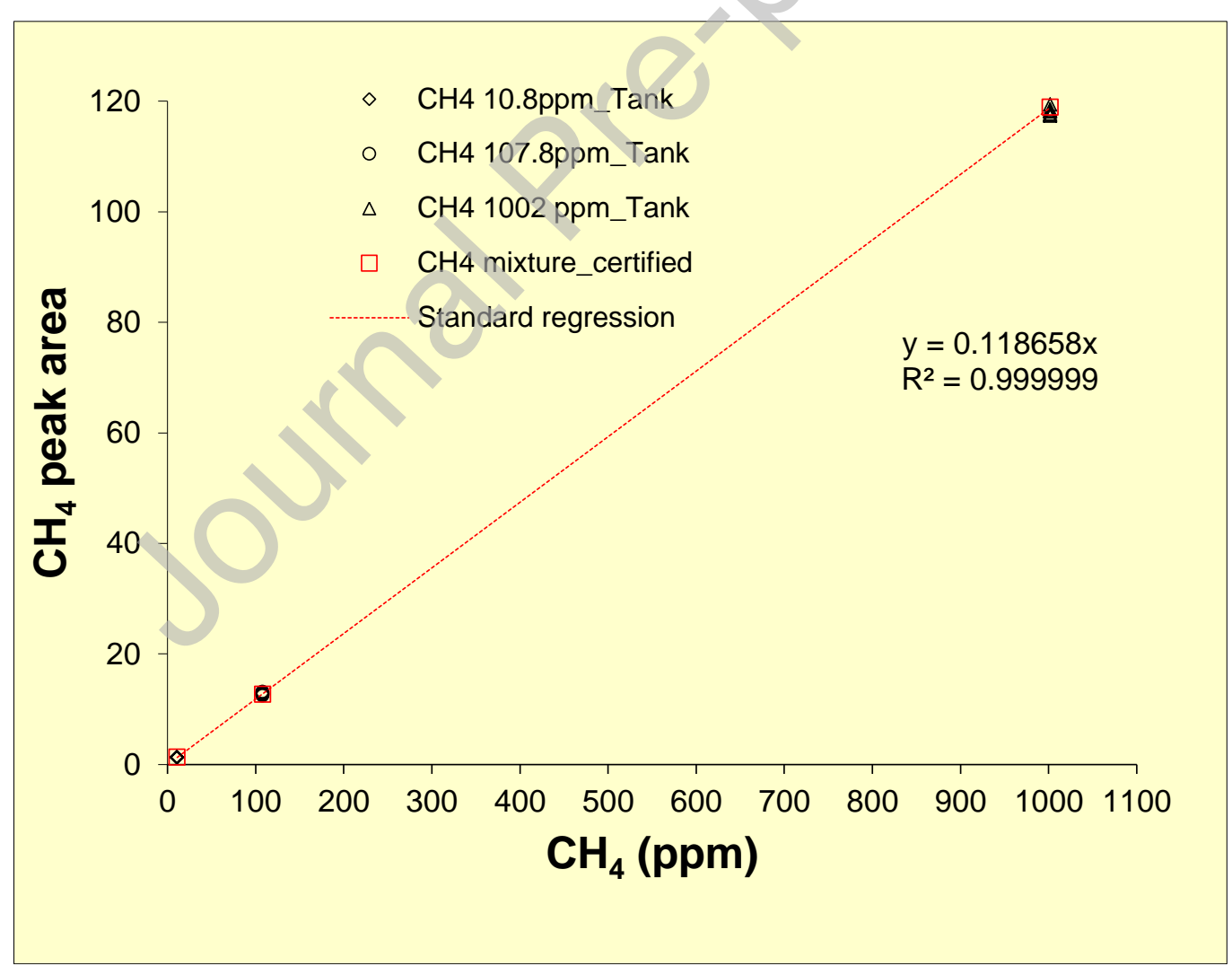

Fig. 4: Calibration of CH4 measured by FID (Agilent 7890A GC): injection of 1ml at 1013 mbar; CH4 standard $10.81 \pm 0.5 ; 107.8 \pm 5$ and $1002 \pm 30$ ppmv, confidence level 95\%, Helium balance. 


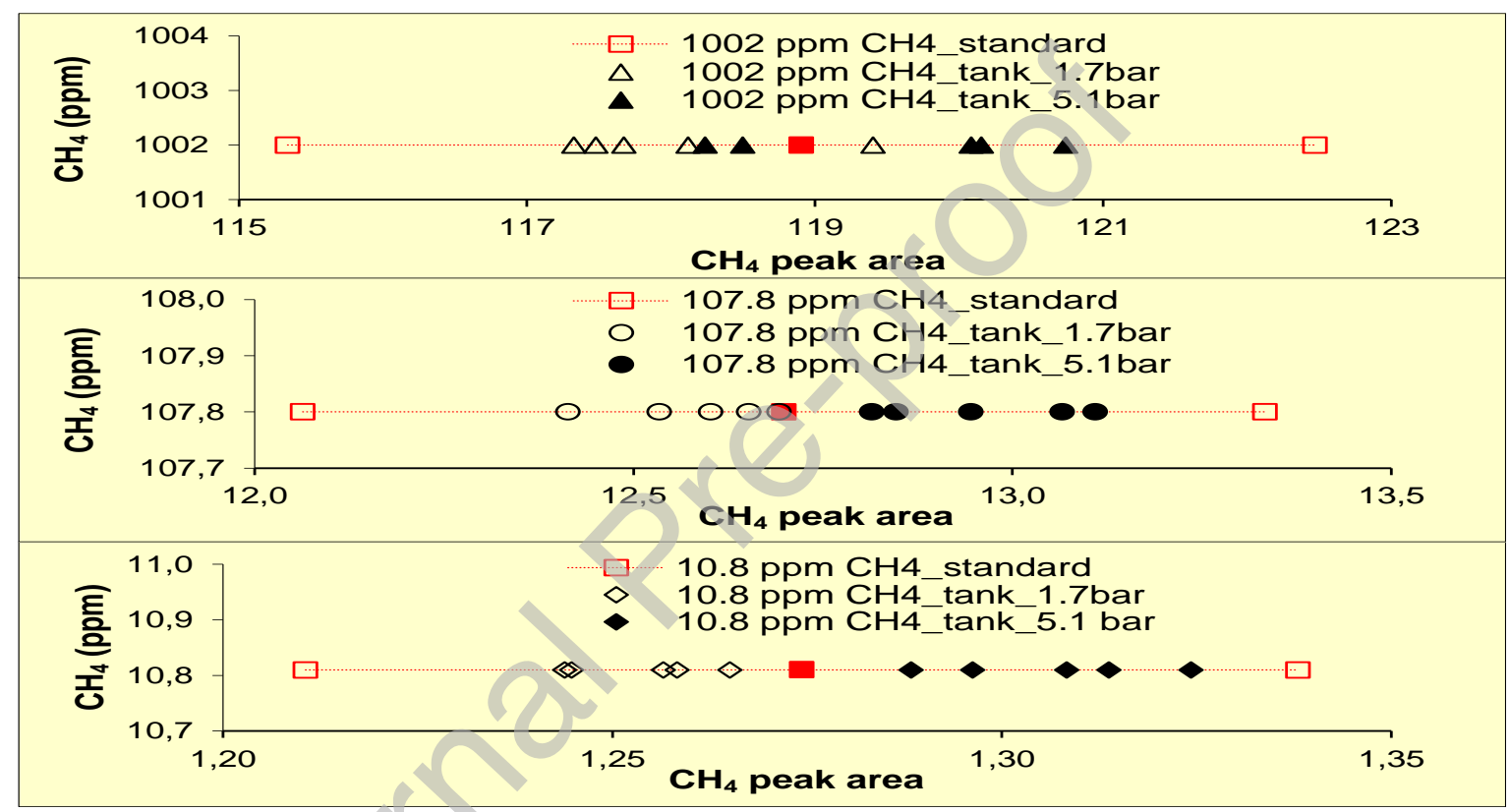

Fig. 5: Comparison of $\mathrm{CH} 4$ mixtures prepared in the tank at two total pressure (1.7 bar and 5.1 bar) with certified mixtures. 


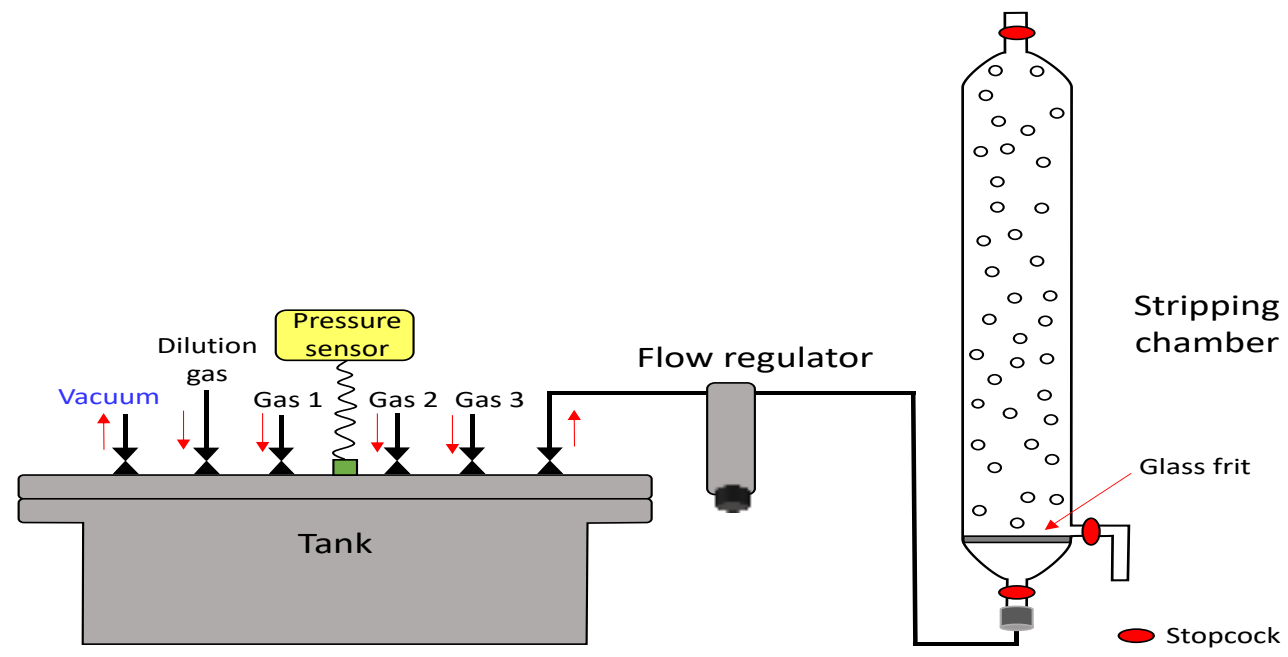

Fig. 6: Schematic diagram of installation for obtaining seawater with a determined amount of CH4.

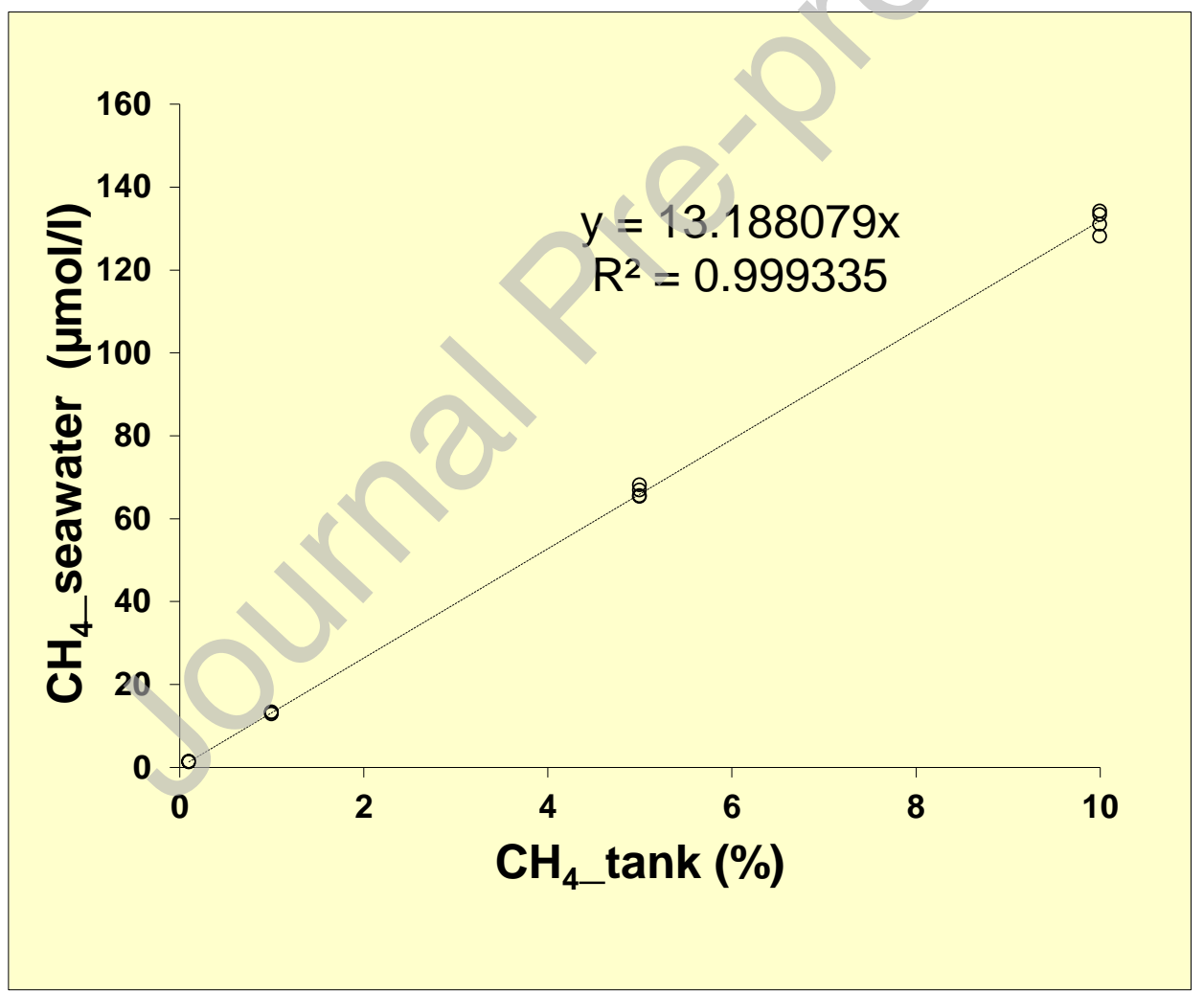

Fig.7: Preparation of seawater enriched with $\mathrm{CH} 4$ by means of the gas calibrator: relation between $\mathrm{CH} 4$ concentration in the seawater and $\mathrm{CH} 4$ concentration in the tank. 
Table 1: Calculation for preparing a 10.8ppm $\mathrm{CH}_{4}$ mixture with the dilution method (diluent gas: helium).

\begin{tabular}{ccccc}
\hline Dilution & $\begin{array}{c}\mathrm{CH}_{4} \text { before } \\
\text { dilution (\%) }\end{array}$ & $\mathrm{PCH}_{4}$ (mbar) & $\begin{array}{c}\text { Total pressure } \\
(\mathrm{mbar})\end{array}$ & $\begin{array}{c}\mathrm{CH}_{4} \text { after dilution } \\
(\mathrm{ppm})\end{array}$ \\
\hline 1 & 100 & 170 & 1700 & 100000 \\
2 & 10.00 & 170 & 1700 & 10000 \\
3 & 1.000 & 170 & 1696 & 1002 \\
4 & 0.1002 & 183 & 1701 & 107.8 \\
5 & 0.0108 & 170 & 1696 & 10.81 \\
\hline
\end{tabular}

Table 2: Results for injection of two standards with the gas injector: injection of 50 $\mu 1$ and $1 \mathrm{ml}$ loops at 1013 mbar pressure, $\mathrm{CH}_{4}$ peak area measured with a FID.

\begin{tabular}{|c|c|c|c|c|c|c|}
\hline & $\begin{array}{l}1013 \mathrm{mbar}_{50 \mu \mathrm{l}} \\
107.8 \mathrm{ppm} \mathrm{CH}_{4}\end{array}$ & $\begin{array}{l}1013 \mathrm{mbar} 1 \mathrm{ml} \\
107.8 \mathrm{ppm} \mathrm{CH}\end{array}$ & Ratio & $\begin{array}{c}1013 \mathrm{mbar}_{50 \mu 1} \\
1002 \mathrm{ppm} \mathrm{CH}_{4}\end{array}$ & $\begin{array}{l}1013 \mathrm{mbar} 1 \mathrm{ml} \\
1002 \mathrm{ppm} \mathrm{CH} \mathrm{CH}_{4}\end{array}$ & Ratio \\
\hline Average value of area & 0.696 & & 18.244 & 6.516 & 118.905 & 18.248 \\
\hline $\operatorname{RSD}(\% ; \mathrm{N}=5)$ & 0.5 & 0.2 & & 0.2 & 0.1 & \\
\hline
\end{tabular}

Table 3: Comparison of certified and prepared mixtures mainly composed of $\mathrm{H}_{2}, \mathrm{CH}_{4}$ and $\mathrm{CO}_{2}$.

\begin{tabular}{ccccccc}
\hline Component & $\begin{array}{c}\text { Standard } \\
\text { composition (\%) }\end{array}$ & $\begin{array}{c}\text { Relative error } \\
(\%)\end{array}$ & Mean area & $\begin{array}{c}\text { Prepared } \\
\text { composition } \\
(\%)\end{array}$ & Mean area* & $\begin{array}{c}\text { Difference** } \\
(\%)\end{array}$ \\
\hline $\mathrm{CH}_{4}$ & 10.04 & 2 & 455123 & 10.04 & 446717 & -1.85 \\
$\mathrm{CO}_{2}$ & 89.96 & 2 & 5745361 & 89.96 & 5746152 & 0.01
\end{tabular}




\begin{tabular}{ccccccc}
$\mathrm{CH}_{4}$ & 19.74 & 2 & 883202 & 19.74 & 864853 & -2.08 \\
$\mathrm{CO}_{2}$ & 19.81 & 2 & 1318175 & 19.80 & 1290880 & -2.07 \\
$\mathrm{~N}_{2}$ & 19.79 & 2 & 19800 & 19.80 & 19563 & -1.20 \\
$\mathrm{He}$ & 40.66 & balance & 289380 & 40.66 & 288569 & -0.28 \\
$\mathrm{H}_{2}$ & 4.859 & 2 & 85484 & 4.859 & 85300 & -0.22 \\
$\mathrm{Ar}$ & 9.56 & 2 & no measured & 9.543 & no measured & \\
$\mathrm{He}$ & 85.581 & balance & 599067 & 85.597 & 605125 & 1.01 \\
$\mathrm{CH}_{4}$ & 5.08 & 2 & 232753 & 5.06 & 232693 & -0.03 \\
$\mathrm{CO}_{2}$ & 10.2 & 2 & 642534 & 10.19 & 631259 & -1.75 \\
$\mathrm{~N}_{2}$ & 10.18 & 2 & 10174 & 10.19 & 10059 & -1.13 \\
$\mathrm{He}$ & 74.54 & balance & 518315 & 74.56 & 520035 & 0.33 \\
$\mathrm{H}_{2}$ & 19.98 & 2 & 346624 & 19.98 & 344084 & -0.73 \\
$\mathrm{Ar}$ & 5.25 & 2 & no measured & 5.24 & no measured & \\
$\mathrm{N}_{2}$ & 19.61 & 2 & 19546 & 19.62 & 19254 & -1.49 \\
$\mathrm{He}$ & 55.16 & balance & 383362 & 55.16 & 378154 & -1.36 \\
$\mathrm{CH}_{4}$ & 0.1002 & 3 & 4724 & 0.1002 & 4680 & -0.93 \\
$\mathrm{CO}_{2}$ & 0.1009 & 3 & 6485 & 0.1002 & 6425 & -0.92 \\
$\mathrm{H}_{2}$ & 0.1005 & 5 & 1799 & 0.1002 & 1830 & 1.73 \\
$\mathrm{He}$ & 99.6984 & balance & 687070 & 99.6994 & 676256 & -1.57 \\
\hline
\end{tabular}

* : five injections

**: Difference between prepared and certified mixtures 